\title{
Knowledge, attitude and practice regarding food poisoning and its prevention in Malaysia: a systematic literature review
}

\author{
${ }^{1}$ Nur Afifah, M.Z., ${ }^{1, *}$ Asma', A. and ${ }^{2}$ Malina, O. \\ ${ }^{1}$ Faculty of Fisheries and Food Science, Universiti Malaysia Terengganu, 21030 Kuala Nerus, Terengganu, \\ Malaysia \\ ${ }^{2}$ Faculty of Medicine and Health Sciences, Universiti Putra Malaysia, 43400 UPM Serdang, Selangor \\ Darul Ehsan, Malaysia
}

\author{
Article history: \\ Received: 4 April 2020 \\ Received in revised form: 14 \\ May 2020 \\ Accepted: 15 May 2020 \\ Available Online: 16 June \\ 2020
}

\section{Keywords:}

Knowledge,

Attitude,

Practice,

Food poisoning,

Malaysia

DOI:

https://doi.org/10.26656/fr.2017.4(6).145

\begin{abstract}
Foodborne diseases, including food poisoning, are becoming a concern as the increasing prevalence of food poisoning and incidents worldwide. This study reviewed previous knowledge, attitudes and practices (KAP) studies on food safety and the prevention of food poisoning in Malaysia. This study also reviewed the behavioural evidence, similarities and differences of the KAP food safety and food poisoning prevention studies in Malaysia and provided an overview of the relationship between KAP level and the socio-demographic profile of the respondents. Sixteen studies covered from 2015 to 2020 (March 2020) were selected. Research was identified through Scopus and Web of Science as main databases and manual searching in Science Direct, PubMed and Springer-Link as the electronic database with Google Scholar as search engines. The journal (research articles) within last five years from 2015 to March 2020, the published articles are easily accessible for researchers, open access with full text, the language was limited to English, and research studies that were done in Malaysia. Knowledge was the most influential factor in the prevention of food poisoning. Ten articles reviewed showed that there was a good level, two studies showed a moderate level, and three studies reported a poor level of knowledge among respondents. For the attitude part, eight studies showed a positive attitude towards food safety attitudes and the prevention of food poisoning with a high level of satisfaction. However, one study had reported that there was a negative attitude to the prevention of food poisoning among respondents. For the practical part, six studies had a good level, two studies showed that there was an average score of food safely towards practices and food poisoning prevention, and one study reported that there were unsatisfactory food safety practices. In the reviewed studies, there was a positive association between KAP's level of food poisoning prevention and its socio-demographic profile, including age, sex, ethnicity, education, income, work experience, and attending food safety and hygiene training. There is a need to improve knowledge, awareness and practice among the community on food safety due to the increase in foodborne disease cases in Malaysia.
\end{abstract}

\section{Introduction}

Foodborne diseases are defined as the toxic or infectious in nature that caused by bacteria, viruses, parasites, or chemical substances that enter the body through contaminated food or water, which can give an infection including severe diarrhoea and meningitis (WHO, 2019). There are five categories of foodborne diseases including cholera, typhoid fever, hepatitis A, dysentery, and food poisoning (i.e. associated with acute gastrointestinal symptoms like diarrhoea and vomiting)
(WHO, 2018). The common symptoms of foodborne diseases are nausea, vomiting, stomach cramps, and diarrhoea (CDC, 2019).

Approximately about two million of fatal cases occur worldwide in a year due to food poisoning particularly in developing countries (WHO, 2019). About 600 million people worldwide fall ill after eating contaminated food, and 420000 fatal cases occur every year. The most common diseases due to digestion of contaminated food are diarrhoeal diseases, which cause 550 million people 
to fall ill and 230000 fatal cases every year, especially in developing countries (WHO, 2019). The incidence rate and cases of food poisoning increased in Malaysia from 2000 to 2017 (Ministry of Health Malaysia, 2018). Growing cases involving the consumption of nonhygienic food are becoming more serious, not just among the public but also among school children, even though numerous attempts have been made by the authorities. Consumer safeguards in food handling are critical to eliminate or reduce the growth of emerging bacteria, avoiding cross-contamination that would prevent foodborne diseases from occurring (Moreb et al., 2017).

Lack of knowledge, attitude and practice to prevent food poisoning can lead to foodborne outbreaks. Food mishandling and poor personal hygiene may allow pathogens to grow and multiply in sufficient numbers and cause human illness (Abdullah, 2015). Understanding the interaction between consumers on the prevailing knowledge, practices and beliefs of food safety can minimize the occurrence of foodborne illness (WHO, 2001). It is, therefore, necessary to educate consumers about the choice of food premises as well as the proper food safety and hygiene guidelines for food preparation at home.

This study reviewed previous knowledge, attitudes and practices (KAP) studies on food safety and the prevention of food poisoning in Malaysia. This study also reviewed the behavioural evidence, similarities and differences of the KAP food safety and food poisoning prevention studies in Malaysia and provided an overview of the relationship between KAP level and the sociodemographic profile of the respondents.

\section{Materials and methods}

\subsection{Exploration resources}

Literature was conducted in March 2020 using Scopus and Web of Science as main databases. Only research articles from 2015 to March 2020 were included. Research articles were chosen because research articles act as the primary sources that offer empirical data (Shaffril et al., 2019). Nevertheless, it should be noted that no database comprehensive or perfect including Scopus and Web of Science (Shaffril et al., 2019). Therefore, this study conducted a manual searching on several established sources including Science Direct, PubMed and Springer-Link as an electronic database with Google Scholar as search engines to obtain the articles regarding KAP towards food poisoning in Malaysia. The language was limited to English and open access with full text.

\subsection{The systematic review process in selecting articles}

\subsubsection{Identification process}

The first process in the systematic review was the identification of keywords, followed by the process of searching the similar and interrelated terms of study based on the previous studies, encyclopedia, dictionaries, and thesaurus. After all relevant and related terms managed to identify, the search strings on Scopus and Web of Science database were conducted in March 2020 (Table 1). Literature was completed using the term "knowledge", "attitude", and "practice", and synonyms for the terms; knowledge = awareness, recognition; attitude $=$ belief, practice $=$ habit. There were five main keywords used to search appropriate studies includes "knowledge", "attitude", "practice", "food poisoning", and "Malaysia". The interchangeable word used in this study was from food poisoning to food safety and food hygiene. The studies that addressed only "knowledge" or "attitude" or "practice" or combination of any two of these terms were included to account the number of articles related to the topic. In total, 165 articles were chosen in the first stage of the systematic literature review process.

\subsubsection{Screening process}

The main purpose of the screening process was to remove duplicate articles and articles that do not meet the inclusion criteria. A total of 110 articles remained in the first stage after the removal of duplicate articles. As previously stated, the inclusion criteria for this review included only journals for the last five years from 2015 to March 2020; published articles in English that are easily accessible to researchers; open access to full text; and was conducted in Malaysia. The exclusion criteria were the publication that is in the form of conference proceeding, chapter in a book, book, book series, metasynthesis, meta-analysis, review and systematic review. As a result, a total of 40 articles remained on the basis of inclusion and exclusion criteria.

\subsubsection{Eligibility process}

A total of 40 articles were prepared for the third process in systematic literature review known as the eligibility. In this stage, the abstract and main contents of all the articles were examined assiduously to achieve the objectives of the current study and to fulfil the inclusion criteria. A total of 24 articles were excluded after reviewing the abstracts and main contents. In total, 16 articles were selected to be reviewed.

\subsection{Data extraction and analysis}

PRISMA table or Preferred Reporting Items for a systematic review is a published standard to conduct a 
Table 1. The search string

\begin{tabular}{|c|c|c|}
\hline Main database & Keywords & Search string \\
\hline \multirow{7}{*}{$\begin{array}{l}\text { Web of Science } \\
\text { (WoS) }\end{array}$} & $\begin{array}{l}\text { Knowledge, attitude, practice, } \\
\text { food poisoning, Malaysia }\end{array}$ & $\begin{array}{l}\text { (TS=(("knowledge*” OR "aware*” OR "recognition") AND ("attitude*” OR } \\
\text { "belief*") AND ("practice*” OR "habit*”) AND ("food safety" OR "food } \\
\text { poisoning" OR "food hygiene") AND "Malaysia")) }\end{array}$ \\
\hline & $\begin{array}{l}\text { Knowledge, attitude, food } \\
\text { poisoning, Malaysia }\end{array}$ & $\begin{array}{l}\text { (TS=(("knowledge*" OR "aware*" OR "recognition") AND ("attitude*" OR } \\
\text { "belief*") AND ("food safety" OR "food poisoning" OR "food hygiene") AND } \\
\text { "Malaysia")) }\end{array}$ \\
\hline & $\begin{array}{l}\text { Knowledge, practice, food } \\
\text { poisoning, Malaysia }\end{array}$ & $\begin{array}{l}\text { (TS=(("knowledge*" OR "aware*” OR "recognition") AND (“practice*” OR } \\
\text { "habit*”) AND ("food safety" OR "food poisoning" OR "food hygiene") AND } \\
\text { "Malaysia")) }\end{array}$ \\
\hline & $\begin{array}{l}\text { Attitude, practice, food } \\
\text { poisoning, Malaysia }\end{array}$ & $\begin{array}{l}\text { (TS=(("attitude*” OR "belief*”) AND ("practice*” OR “habit*”) AND (“food } \\
\text { safety" OR "food poisoning" OR “food hygiene") AND “Malaysia")) }\end{array}$ \\
\hline & $\begin{array}{l}\text { Knowledge, food poisoning, } \\
\text { Malaysia }\end{array}$ & $\begin{array}{l}\text { (TS=(("knowledge*” OR “aware*” OR “recognition") ("food safety" OR "food } \\
\text { poisoning" OR "food hygiene") AND "Malaysia")) }\end{array}$ \\
\hline & $\begin{array}{l}\text { Attitude, food poisoning, } \\
\text { Malaysia }\end{array}$ & $\begin{array}{l}\text { (TS=(("attitude*” OR "belief*”) AND ("food safety" OR "food poisoning" OR } \\
\text { "food hygiene") AND "Malaysia")) }\end{array}$ \\
\hline & $\begin{array}{l}\text { Practice, food poisoning, } \\
\text { Malaysia }\end{array}$ & $\begin{array}{l}\text { (TS=(("practice*” OR "habit*”) AND ("food safety" OR "food poisoning" OR } \\
\text { "food hygiene") AND "Malaysia")) }\end{array}$ \\
\hline \multirow{7}{*}{ Scopus } & $\begin{array}{l}\text { Knowledge, attitude, practice, } \\
\text { food poisoning, Malaysia }\end{array}$ & $\begin{array}{l}\text { TITLE-ABS-KEY((“knowledge*” OR "aware*” OR "recognition") AND } \\
\text { ("attitude*” OR "belief*”) AND ("practice*” OR "habit*”) AND ("food safety" } \\
\text { OR "food poisoning" OR "food hygiene") AND "Malaysia") }\end{array}$ \\
\hline & $\begin{array}{l}\text { Knowledge, attitude, food } \\
\text { poisoning, Malaysia }\end{array}$ & $\begin{array}{l}\text { TITLE-ABS-KEY((“knowledge*” OR "aware*” OR "recognition") AND } \\
\text { ("attitude*” OR "belief*”) AND ("food safety" OR "food poisoning” OR "food } \\
\text { hygiene") AND "Malaysia") }\end{array}$ \\
\hline & $\begin{array}{l}\text { Knowledge, practice, food } \\
\text { poisoning, Malaysia }\end{array}$ & $\begin{array}{l}\text { TITLE-ABS-KEY((“knowledge*” OR “aware*” OR "recognition") AND } \\
\text { ("practice*” OR "habit*”) AND ("food safety" OR “food poisoning” OR "food } \\
\text { hygiene") AND "Malaysia") }\end{array}$ \\
\hline & $\begin{array}{l}\text { Attitude, practice, food } \\
\text { poisoning, Malaysia }\end{array}$ & $\begin{array}{l}\text { TITLE-ABS-KEY(("attitude*” OR "belief*") AND ("practice*" OR "habit*”) } \\
\text { AND ("food safety" OR "food poisoning" OR "food hygiene") AND } \\
\text { "Malaysia") }\end{array}$ \\
\hline & $\begin{array}{l}\text { Knowledge, food poisoning, } \\
\text { Malaysia }\end{array}$ & $\begin{array}{l}\text { TITLE-ABS-KEY((“knowledge*” OR "aware*” OR "recognition”) ("food } \\
\text { safety" OR "food poisoning" OR "food hygiene") AND "Malaysia") }\end{array}$ \\
\hline & $\begin{array}{l}\text { Attitude, food poisoning, } \\
\text { Malaysia }\end{array}$ & $\begin{array}{l}\text { TITLE-ABS-KEY((“attitude*” OR “belief*”) AND ("food safety" OR “food } \\
\text { poisoning" OR “food hygiene") AND “Malaysia") }\end{array}$ \\
\hline & $\begin{array}{l}\text { Practice, food poisoning, } \\
\text { Malaysia }\end{array}$ & $\begin{array}{l}\text { TITLE-ABS-KEY(("practice*" OR "habit*") AND ("food safety" OR "food } \\
\text { poisoning" OR "food hygiene") AND "Malaysia") }\end{array}$ \\
\hline
\end{tabular}

Identification:

Research identified through Scopus and Web of Science as main databases and manual searching in Science Direct, PubMed and Springer-Link as electronic database with Google Scholar as search engines $(\mathrm{N}=165)$

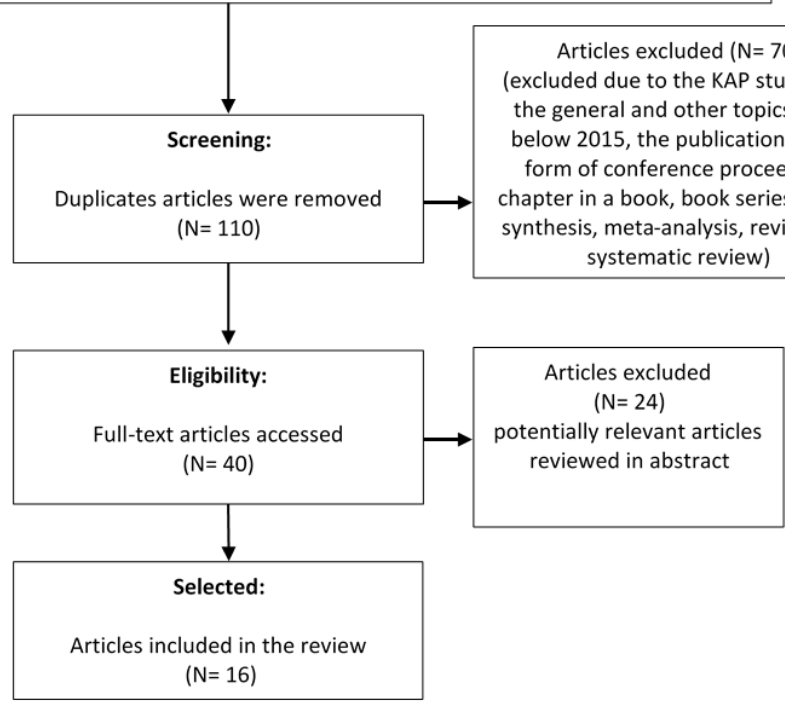

Figure 1. Study selection process

systematic literature review. A publication standard is required to guide the researchers to obtain the related and necessary information that will enable them to examine and evaluate the thoroughness and quality of a review (Shaffril et al., 2019). Sierra et al. (2015) had claimed that PRISMA can identify the inclusion and exclusion criteria for a particular study and is often used within medical studies. The PRISMA table was adopted and used in this study by reporting the main process in conducting a systematic literature review which includes identification, screening and eligibility process. A flow diagram for the study selection process is shown in Figure 1. Further consideration of Malaysia as a country, the articles included in the review led to 16 studies. The following data were extracted from the selected articles: KAP constructs (Knowledge, Attitude, Practice), authors, publication year, sample size, study area/district, and main outcomes as shown in Table 2.

\subsection{General study characteristic}

A total of 16 studies on knowledge, attitude and practice regarding food poisoning in Malaysia covered from 2015 to March 2020 were selected. 16 reviewed articles included on knowledge, attitude and practice 


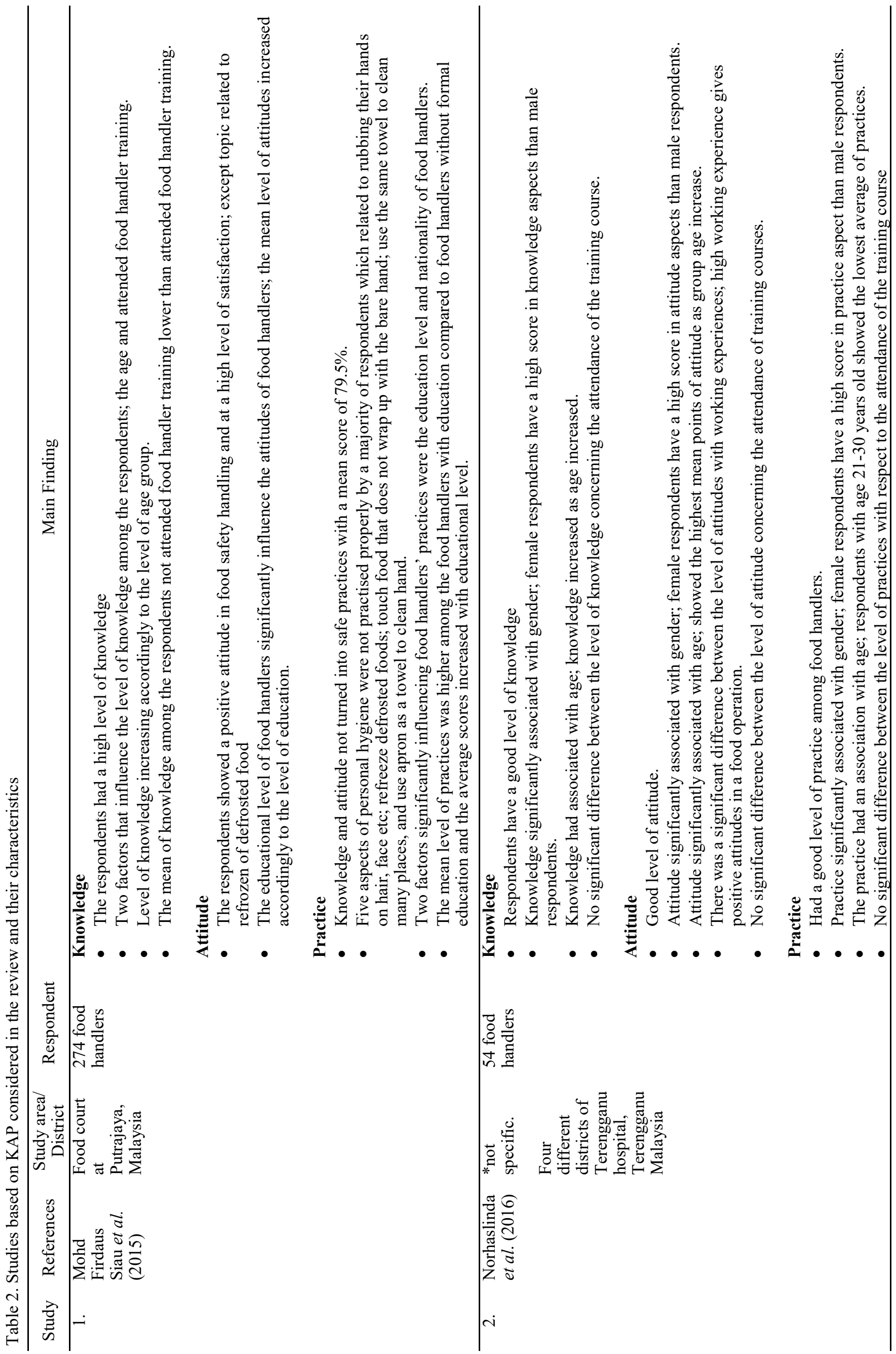




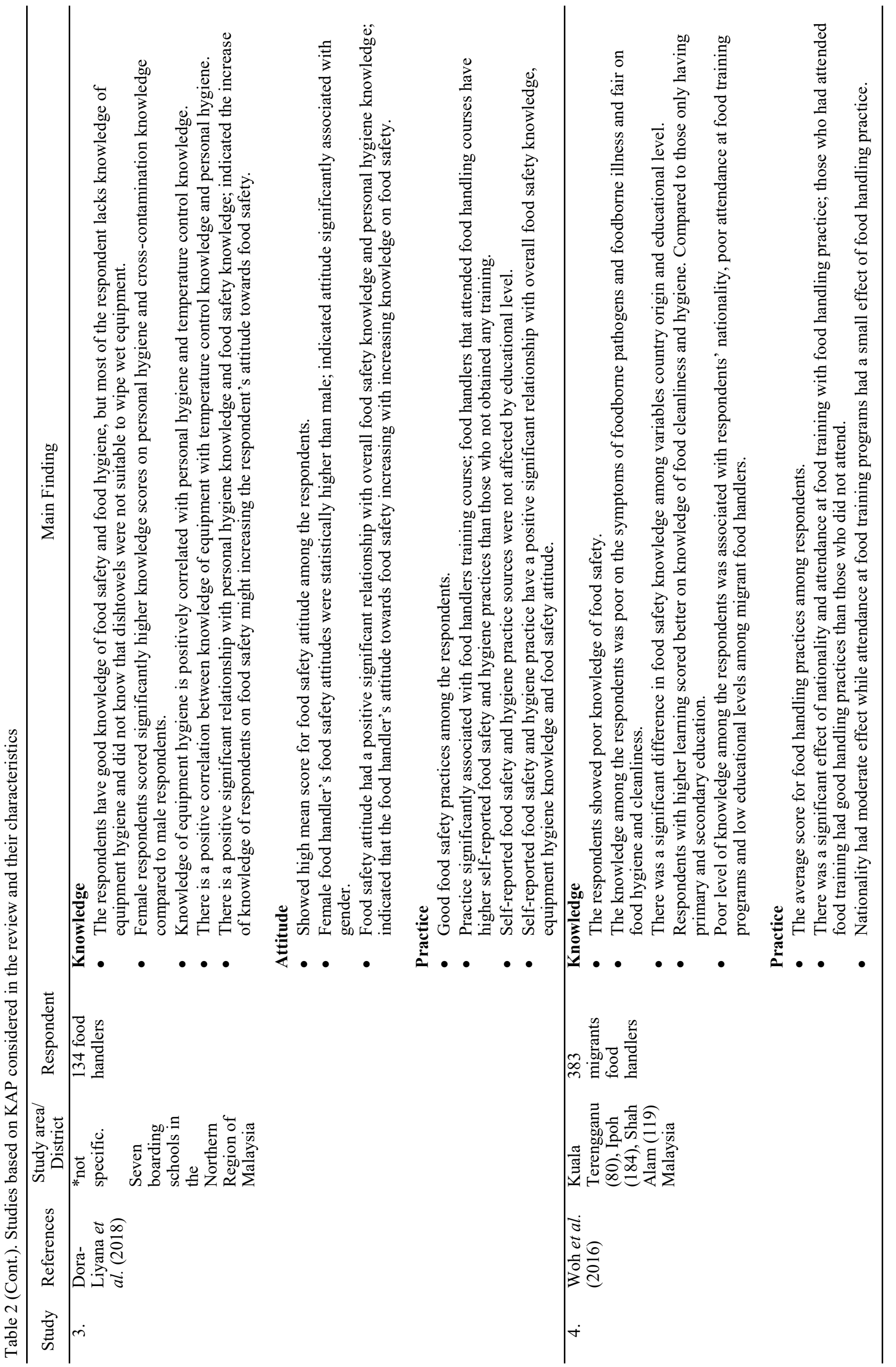




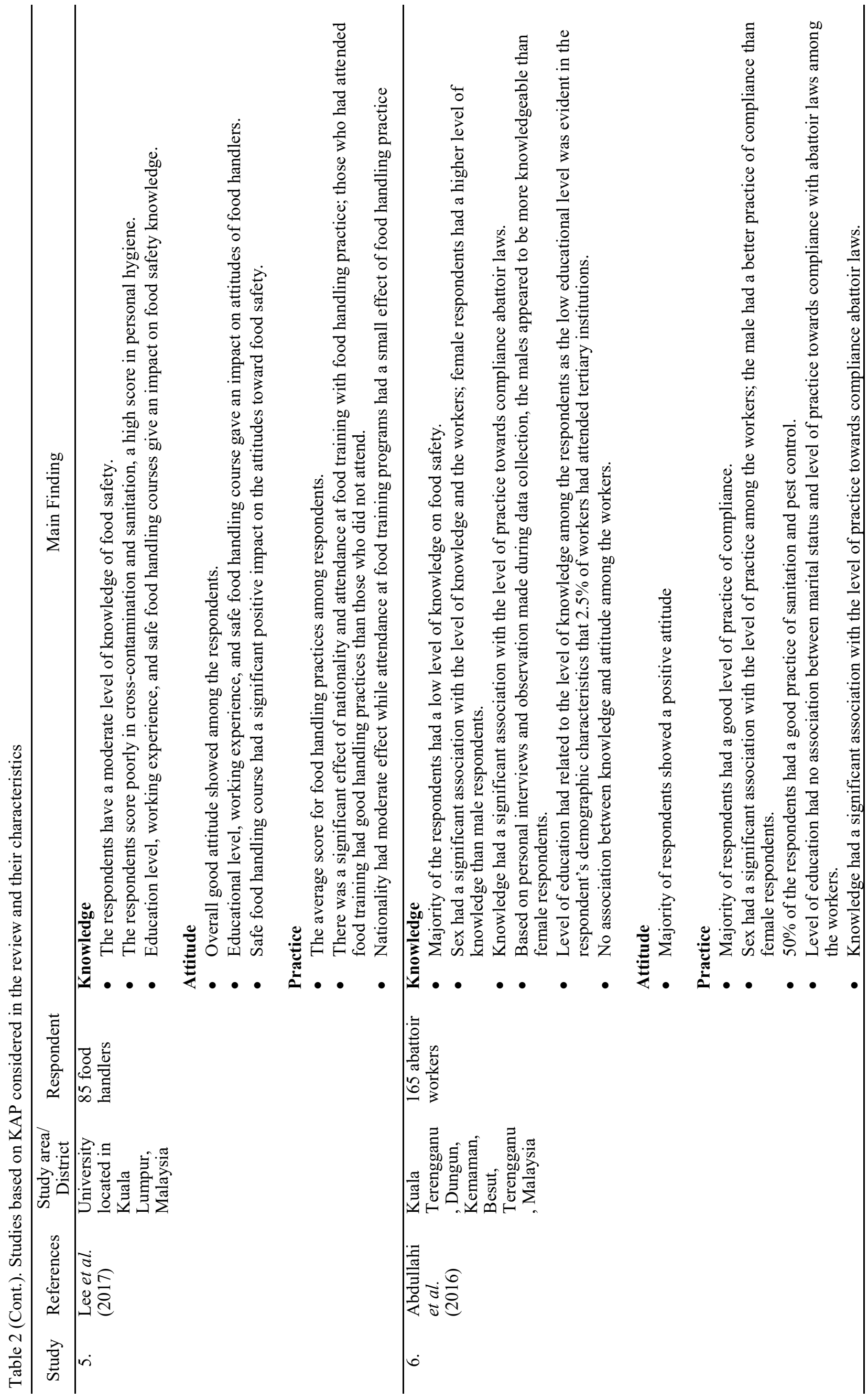




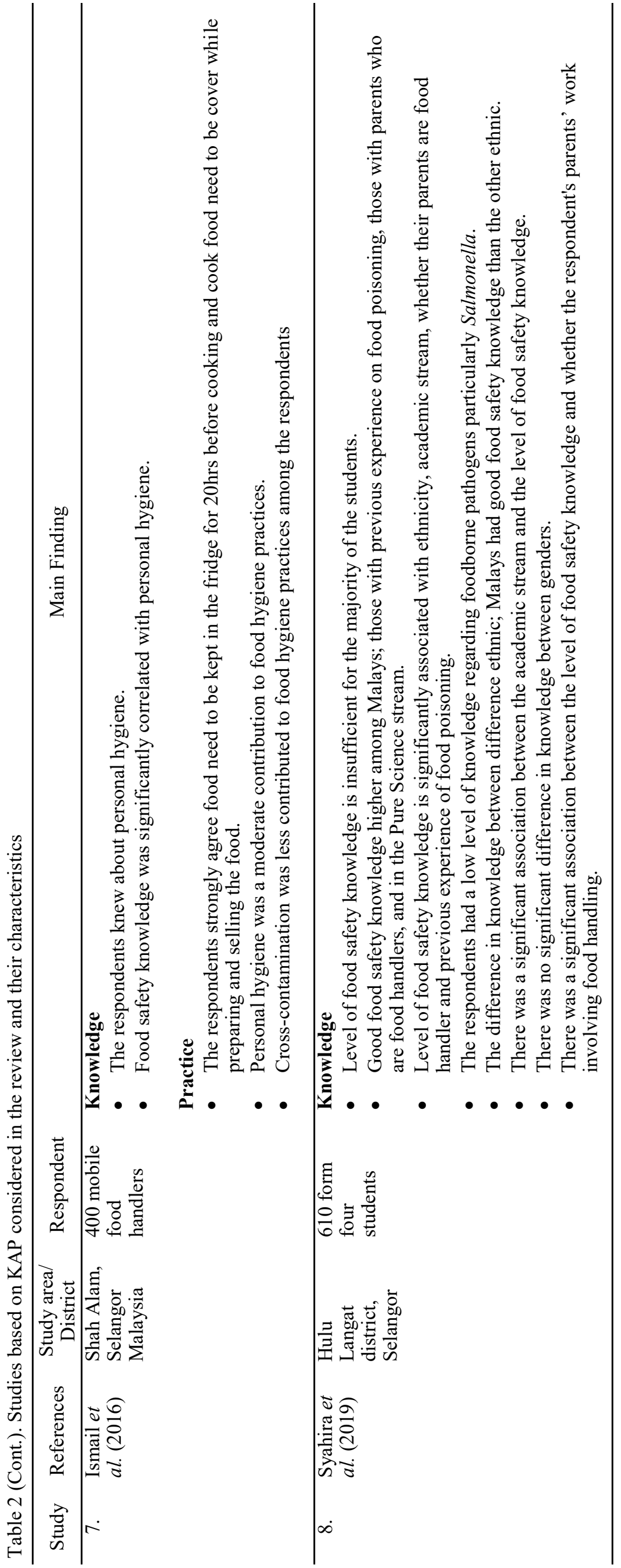




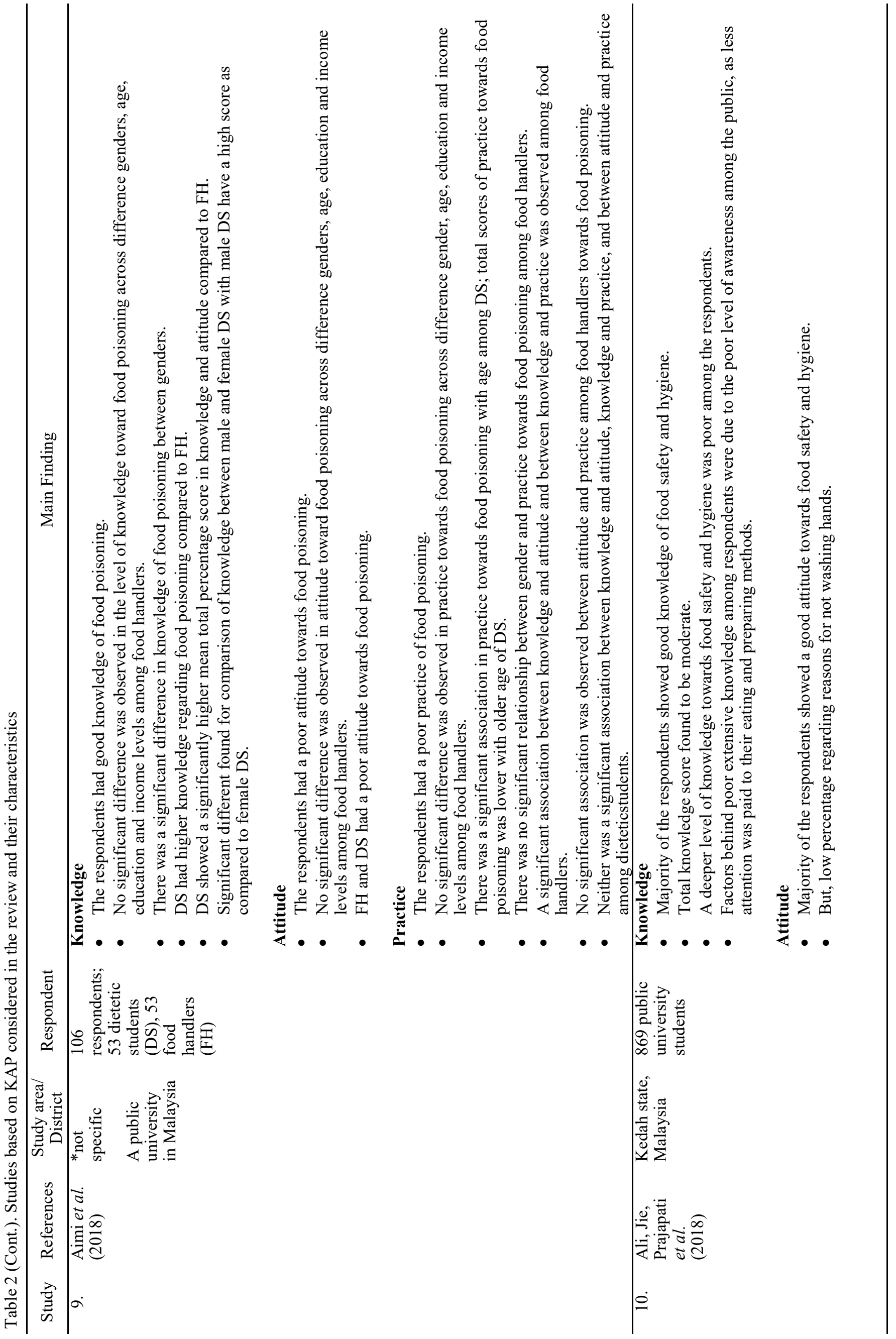




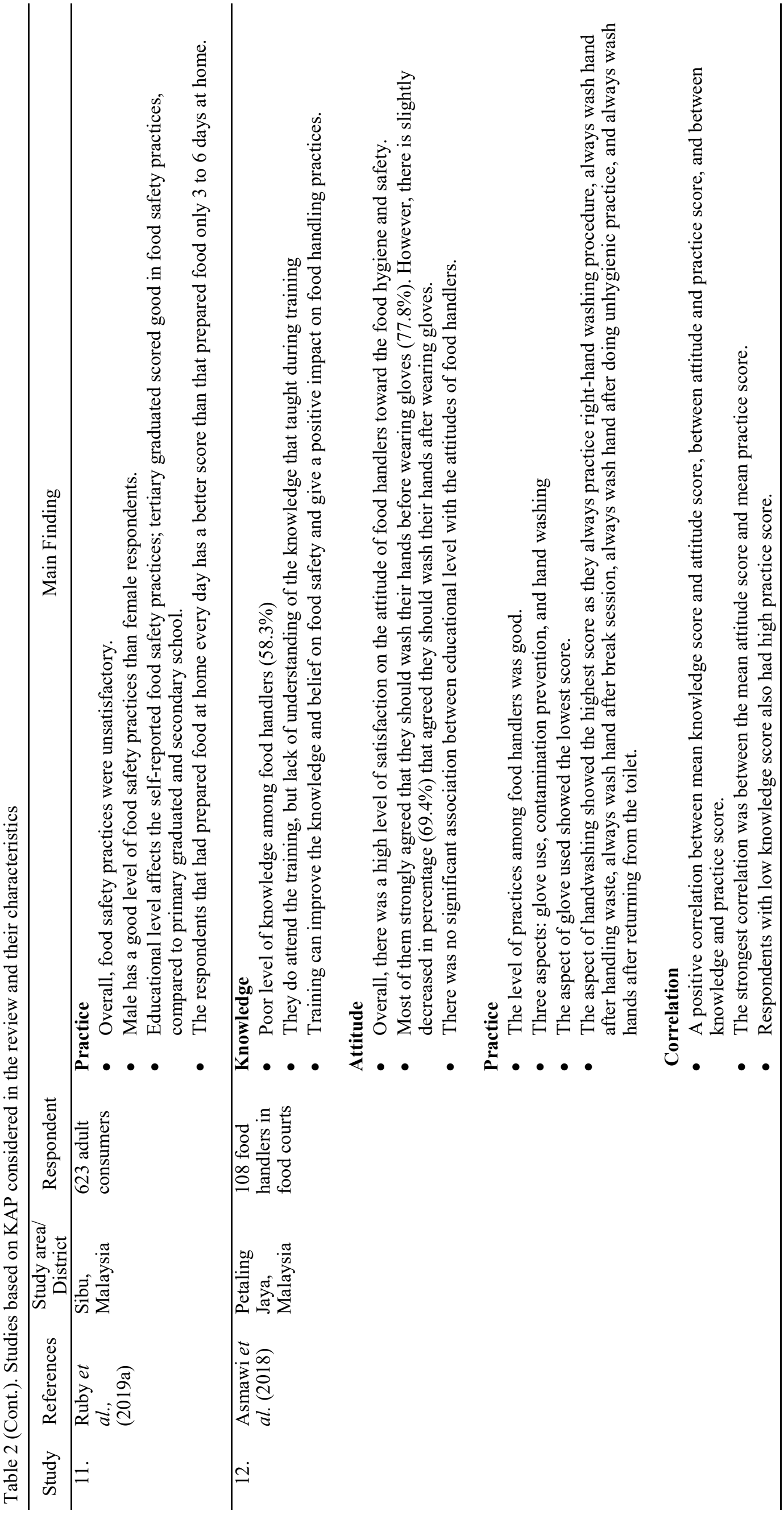




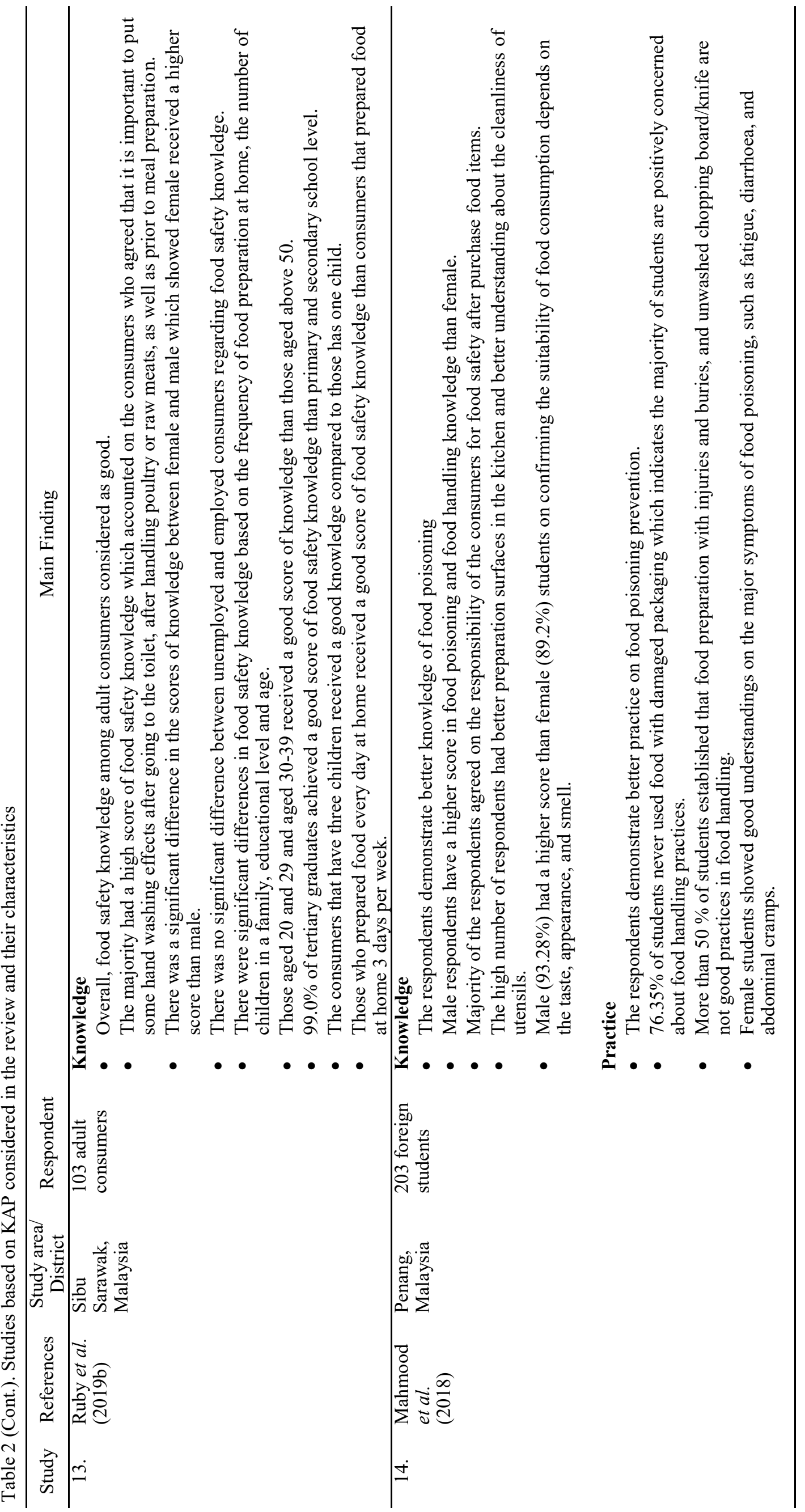




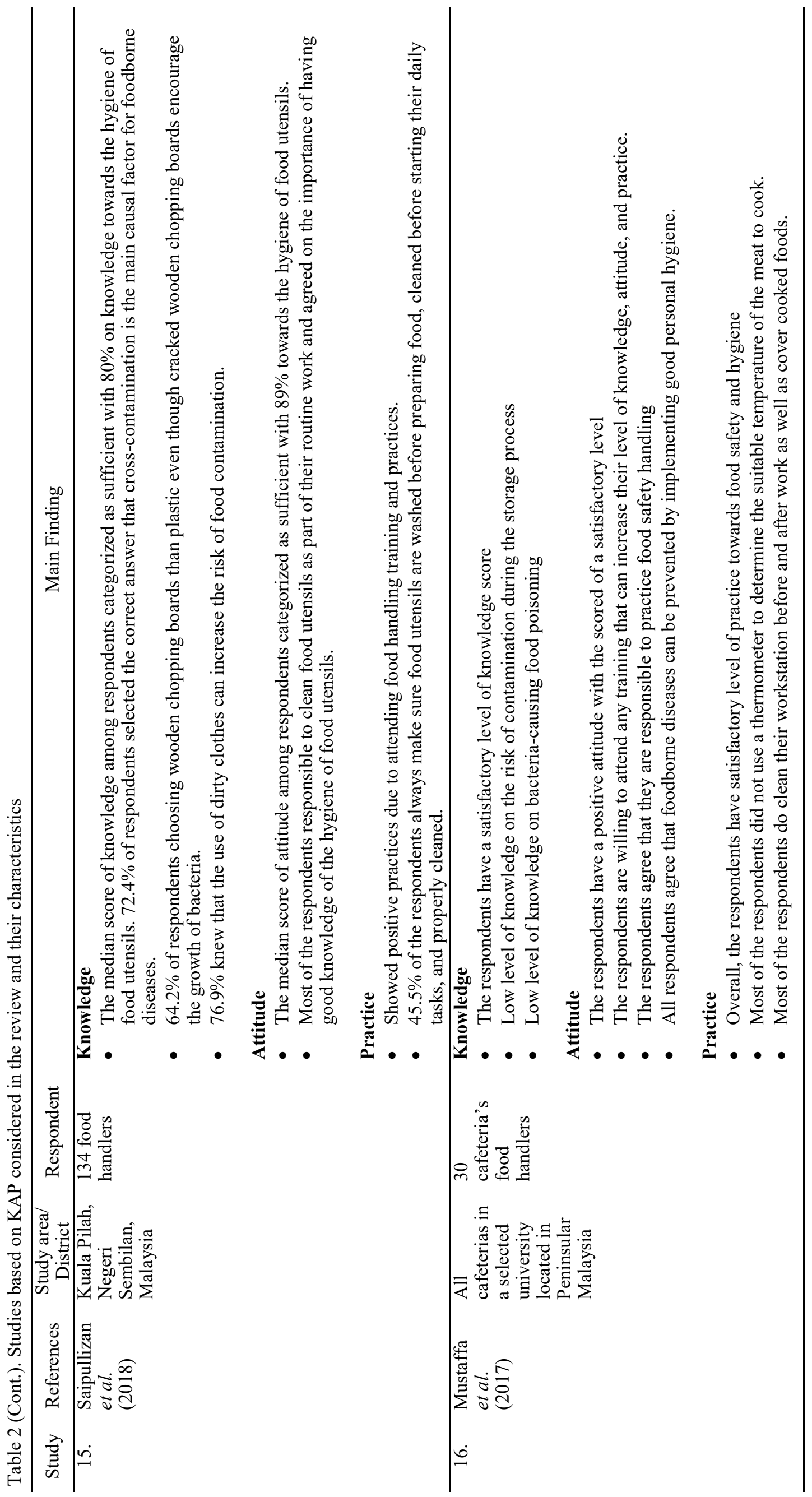


(KAP) $(\mathrm{n}=10$ articles); knowledge and practice $(\mathrm{n}=3$ articles); knowledge ( $\mathrm{n}=2$ articles); and practice $(\mathrm{n}=1$ article). Nine articles focusing on food handlers, one article on abattoir workers, three articles on students, one article was focusing on evaluating the level of KAP among both students and food handlers, and two articles were focusing on consumers. One study was done in Kuala Pilah, Negeri Sembilan (Saipullizan et al., 2018); one study in Penang (Mahmood et al., 2018); one study in Putrajaya (Mohd Firdaus Siau et al., 2015); three studies in Terengganu (Abdullahi et al., 2016; Norhaslinda et al., 2016; Woh et al., 2016); one study in Ipoh (Woh et al., 2016); two studies in Shah Alam (Ismail et al., 2016; Woh et al., 2016); one study in Kuala Lumpur (Lee et al., 2017); one study in Selangor (Syahira et al., 2019); one study in Kedah (Ali, Jie, Prajapati et al., 2018); two studies in Sarawak (Ruby et al., 2019a; Ruby et al., 2019b); and lastly one study was conducted in Petaling Jaya (Asmawi et al., 2018).

\section{Results and discussion}

The different targeted population and sociodemographic profile of respondents were the major elements that may influence the results in KAP studies (Ajibola et al., 2018). The results were focused on the differences and similarities of the level of knowledge, attitude and practice towards food poisoning and its prevention among respondents; the relationship between the level of KAP and socio-demographic profile which give a variety results in KAP studies; as well as the relationship between knowledge, attitude and practice.

\subsection{Knowledge towards food poisoning}

Food safety knowledge was the most influential factors in predicting food hygiene practices (Ismail et al., 2016). Overall, ten articles reviewed showed that there was a good level, two studies showed a moderate level, and three studies reported a poor level of knowledge among respondents.

Four reviewed articles on KAP level among students had reported that there were three studies showed a good level of knowledge among students on food poisoning prevention (Aimi et al., 2018; Ali, William, Prajapati et al., 2018; Mahmood et al., 2018). However, the results were contrasted with a study conducted by Syahira et al. (2019) in Selangor among form four students which had reported that level of food safety knowledge was insufficient for the majority of the students. Meanwhile, one review article among consumers reported by Ruby et al. (2019b) which conduct a study in Sibu Sarawak, Malaysia had reported that the level of food safety knowledge among respondents was considered as good. On the basis of these results, the different outcomes of the level of knowledge among respondents due to the different population were agreed.

Differences in the level of knowledge between respondents can differ due to their socio-demographic characteristics, including age, gender, work experience, educational level, ethnicity, as well as their attendance at any food handler training. Two studies have shown that there is an important correlation between the level of knowledge and age group (Mohd Firdaus Siau et al., 2015; Norhaslinda et al., 2016). Such results are consistent with a study conducted by Mohd Firdaus Siau et al. (2015) among food handlers in Putrajaya which found that the level of knowledge increased accordingly to the age group level. However, the findings contrasted with the research by Aimi et al. (2018) between food handlers and dietary students at a public university in Malaysia, which indicated that there was no significant correlation between the level of knowledge and age.

Next, undergoing food safety and hygiene training is also one of the reasons that lead to the disparity in knowledge. Three studies have shown that food safety and hygiene training has been related to the level of knowledge among respondents (Mohd Firdaus Siau et al., 2015; Woh et al., 2016; Lee et al., 2017). The findings were confirmed by an earlier study conducted by Halim et al. (2014) among food handlers at public university in Malaysia, which indicated that there was a positive correlation between the level of knowledge and attending food handlers training. Mohd Firdaus Siau et al. (2015) stated the level of knowledge among food handlers who attended food handler training was better than those who did not attend the food handler training. This finding can be explained by the fact that during food safety and hygiene training, participants were exposed to disease aetiology related to foodborne pathogens, personal hygiene, proper and appropriate food handling as well as cause and effect of not strictly following the food safety guidelines particularly among food handlers, as most of the food poisoning cases occurred at the restaurant.

As set out in the Food Hygiene Regulations 2009 and the Food Act 1983, enacted by the Food Safety and Quality Division (FSQD), commercial food handlers are exposed to the attend food safety courses (Food Safety and Quality Division Ministry of Health Malaysia, 2016; Ruby et al., 2019a) and to be monitored by the authorities. However, the result contrasted with a study conducted by Norhaslinda et al. (2016) on the assessment of KAP Good Manufacturing Practices (GMP) among food handlers at Terengganu's Hospital, which reported that there was no substantial difference between the level of knowledge and attendance at the 
training course. A reviewed Abdullahi et al. (2016) on evaluating the level of knowledge, attitude and practices among abattoir workers had shown that there was no attending training that could lead to differences in the level of knowledge.

Four reviewed studies showed there was a significant association between the level of knowledge and gender (Abdullahi et al., 2016; Norhaslinda et al., 2016; Aimi et al., 2018; Dora-Liyana et al., 2018). Three studies had reported that the female respondents have a higher level of knowledge towards food safety than male respondents (Norhaslinda et al., 2016; Aimi et al., 2018; Dora-Liyana et al., 2018). However, the results contrast with a study by Abdullahi et al. (2016) that had reported that male had a high level of knowledge based on personal interview and observation during data collection among the abattoir workers.

One reviewed study showed the level of knowledge had an association with working experience (Lee et al., 2017). Lee et al. (2017) had reported that those who had more working experience in the food industry had better overall food safety knowledge. They might had been taught and experienced in food safety and hygiene due to some training has been given by their company. Four studies reported that educational level had associated significant association towards the level of knowledge (Abdullahi et al., 2016; Woh et al., 2016; Lee et al., 2017; Syahira et al., 2019). Woh et al. (2016) had reported that the respondents with higher learning level of education scored better on knowledge compared to those only having primary and secondary education. These results were contrasted with a study conducted by Aimi et al. (2018) which revealed that there was no significant difference observed in the level of knowledge towards food poisoning across difference gender, age, education level and income levels among food handlers. These results were similar with a study conducted by Rosnani et al. (2014) which had reported that there were no significant differences on knowledge when compared to ethnicity for Malaysians, nationality, monthly income, age groups, education status, working experiences and attended training before being engaged as food workers.

\subsection{Attitude towards food poisoning}

For the attitude part, eight studies showed a positive attitude towards food safety and the prevention of food poisoning with a high level of satisfaction. However, one study had reported that there was a negative attitude to the prevention of food poisoning among respondents.

Overall, the reviewed articles revealed that there were seven studies showed a positive attitude with a high level of satisfaction among food handlers (Mohd Firdaus
Siau et al., 2015; Norhaslinda et al., 2016; Lee et al., 2017; Mustaffa et al., 2017; Dora-Liyana et al., 2018; Asmawi et al., 2018; Saipullizan et al., 2018) and among abattoir workers (Abdullahi et al., 2016). The results were contrasted with a study conducted by Aimi et al. (2018) among food handlers in a public university in Malaysia which showed there were poor attitude towards food poisoning prevention among respondents. On the other hand, a reviewed study conducted among public university students in Kedah state, Malaysia by Ali, William, Prajapati et al. (2018) had reported that there was a positive attitude among students.

One reviewed study had reported that there was an association between level of attitude and age among respondents with the age group of 21-30 years old showed the lowest average mean points of attitude (Norhaslinda et al., 2016). One reviewed study revealed that attendance food handler training had associated with the level of attitude among food handlers (Lee et al., 2017). The finding was confirmed by a study conducted between food handlers at residential colleges and canteens on food safety KAP by Nee and Sani (2011) and stated that respondents who attended courses had a better attitude to food handling than those who did not attend the course on food handling. The findings were similar to those of a study conducted by Rosnani et al. (2014) to access food safety knowledge, attitudes and practices among restaurant staff in Putrajaya, and this study confirms that there were substantial gaps between trained and untrained employees. Thus, attending a food handler training may have an effect on the attitudes of food handlers (Lee et al., 2017). However, the results were contrasted with a study conducted in Terengganu among food handlers by Norhaslinda et al. (2016) which had reported that there was no significant difference between the level of attitude to attendance of training courses.

The association between the level of attitude with gender, working experience, and educational level had been reported in earlier studies. Two reviewed studies showed there was an association between level of attitude among respondents with the gender. Female respondents have higher grades in attitude aspects than male respondents (Norhaslinda et al., 2016; Dora-Liyana et al., 2018). Two reviewed studies had reported that there was an association between level of attitude with the working experience which those who had more working experience had a better score of attitude on food safety than those had short duration of working experiences (Norhaslinda et al., 2016; Lee et al., 2017). Three studies reported the educational level was associated with the level of attitude among respondents (Rosnani et al., 2014; Woh et al., 2016; Lee et al., 2017). 
Abdul-Mutalib et al. (2012) also had reported that there was a correlation between education level and attitude. Lee et al. (2017) had reported that the higher the education level, the better the impact on attitudes of the food handler. However, the results were contrasted with a study conducted by Aimi et al. (2018) which had reported that there was no significant difference was observed in attitude toward food poisoning across difference genders, age, education and income levels among food handlers.

\subsection{Practice towards food poisoning}

Overall, for the practical part, six studies had a good level, two studies showed that there was an average score of food safety practices and food poisoning prevention, and one study reported that there were unsatisfactory food safety practices.

The reviewed studies showed that there were six studies had a good level of practice on food safety and food poisoning prevention among food handlers (Norhaslinda et al., 2016; Dora-Liyana et al., 2018; Asmawi et al., 2018; Saipullizan et al., 2018) and abattoir workers (Abdullahi et al., 2016). However, the results were contrasted with a study conducted among migrant food handlers in Kuala Terengganu, Ipoh, and Shah Alam Malaysia by Woh et al. (2016) and a study conducted among food handlers in a university located in Kuala Lumpur Malaysia by Lee et al. (2017) reported that there was an average score for food handling practices among respondents. A study on self-reported food safety practices among adult consumers conducted by Ruby et al. (2019a) in Sibu Sarawak had revealed that the food safety practices among respondents were unsatisfactory. This might indicate that the future study needs to be more concern and focus on consumers as they are more exposed to the food poisoning by buying food outside and Mahmood et al. (2018) had revealed that the food from restaurants is the main cause of food poisoning to occur as improper and not strictly followed the food safety practices. However, Ruby et al. (2019a) had stated that the majority of food poisoning cases occur was due to improper food handling and preparation at home. Therefore, it is also important to educate the consumers on choosing the food premises and proper guideline on food safety, as they also prepared food at home.

The reviewed studies reported that there were associated with the level of practice among respondents with sociodemographic characteristics such as age, attendance food handler training, gender, educational level, nationality, and vaccination. Three studies reported that there was an association between level of practice among respondents with the age group (Rahman et al.,
2012; Norhaslinda et al., 2016; Aimi et al., 2018). Norhaslinda et al. (2016) had reported that practice had an association with age; respondents with age 21-30 years old showed the lowest average of practices. These results were proved by Ali, William, Prajapati et al. (2018) which stated that a number of studies found that poor food handling practices were among the respondents with ages of 18-29 with education above high school level 1.

Four studies reported that attendance of food handler training had associated with the level of practice among respondents (Rahman et al., 2012; Halim et al., 2014; Woh et al., 2016; Dora-Liyana et al., 2018); those who had attended the food handler training had better practice in food safety and hygiene than those who had not attended. However, a reviewed study by Abdullahi et al. (2016) which to evaluate the level of knowledge, attitude and practices among abattoir workers had no report on the attending training might cause differences in the level of knowledge. It is compulsory for the abattoir workers that handling with fresh food to registered with the ministry as required in the Abattoirs (Privatization) Act 1993 (Commissioner of Law Revision Malaysia, 2006) and they are required to ensure that their surrounding areas and premises in the pollution-free and hygienic conditions (Ruby et al., 2019b). Therefore, more efforts are needed to improve the level of practices among food handlers and abattoir workers as cross-contamination might occur if they did not strictly follow the food safety guidelines and caused food poisoning.

Two reviewed studies had reported that the level of practice among respondents had significantly associated with gender (Abdullahi et al., 2016; Norhaslinda et al., 2016). Earlier studies by Nee and Sani (2011); Norhaslinda et al. (2016); and Rosnani et al. (2014) had reported that female respondents have high grades in practice aspects than male respondents. This is because the female is more likely to be involved in food handling and preparing activities as well as providing food for households since they are traditionally responsible for (Auad et al., 2019). Contrast with the study by Abdullahi et al. (2016) which evaluated the abattoir workers in Terengganu as reported that male respondents had a better practice of compliance than female respondents, in handling fresh meat.

Two studies showed that the level of practice had significantly associated with the educational level (Rosnani et al., 2014; Mohd Firdaus Siau et al., 2015). Mohd Firdaus Siau et al. (2015) had reported that the mean level of practices was higher among food handlers with education compared to food handlers without formal education. However, Aimi et al. (2018) had 
evaluated food handlers and dietetic students in a public university in Malaysia, had reported that there was no significant difference was observed in practice towards food poisoning across difference genders, age, education and income levels among food handlers, but there was a significant association in practice toward food poisoning with age among dietetic students.

Halim et al. (2014) had used correlation to examine the association between sociodemographic variables and KAP regarding hygiene status of food premises among food handlers at the cafeterias of a public university in Malaysia. The result showed that there was a significant difference between the relationship of hygiene status of food premises and food handlers with their working experiences, KAP score with training attended and vaccination received; no significant association between KAP score and overall hygiene status of food handler and food premises. This indicated those who had highest working experience had the highest percentage of good hygiene status compared to those had less working experience, and those who had undergone training and vaccination had a higher percentage of good overall KAP score.

\subsection{Relationship between knowledge, attitude and practice towards food poisoning prevention}

There was a positive relationship between knowledge and attitude; attitude and practice which might indicate that the level of knowledge affects the score of attitude and the level of attitude will affect the level of practices on food safety and food poisoning prevention (Mohd Firdaus Siau et al., 2015; Norhaslinda et al., 2016). The result contrasted with a study conducted by Abdullahi et al. (2016) which had reported that there was a statistically significant association between knowledge and level of practice toward compliance with abattoir laws, but no association between knowledge and attitude among the workers; and also no association between attitude and practice of compliance with the abattoir laws among workers.

Ali, William, Prajapati et al. (2018) had examined the correlation between total knowledge, total attitude and total perception against KAP scores among public university students in Kedah. The result showed that there were significant strong positive correlations between total knowledge, total attitude and total perception. The results were supported by a previous study conducted by Rosnani et al. (2014) among food handlers in Putrajaya which showed that there was a strong relationship between knowledge, attitude, and practice about food safety. The results indicated that as knowledge increase, attitude and practice will improve accordingly.
Food safety knowledge was significantly correlated with personal hygiene (Ismail et al., 2016). The result was similar with a study conducted by Dora-Liyana et al. (2018) in seven boarding schools in the northern region in Malaysia which reported that there was a positive significant relationship between food safety knowledge and personal hygiene knowledge and indicates that the increase of knowledge on food safety might increase the attitude towards food safety among respondents. However, the result contrasted with a study conducted by Ali, William, Prajapati et al. (2018) which had reported that the students have a good level of knowledge, however, there was a negative attitude on personal hygiene had revealed. A study conducted by Mohd Firdaus Siau et al. (2015) had revealed that the high level of knowledge and positive attitude on food safety and food poisoning prevention not necessarily turned into safe practices. Nevertheless, it still can conclude that the people with high food safety and food poisoning knowledge are more likely to have a positive attitude and practices towards safe food preparation and food poisoning prevention (Ruby et al., 2019b). All of the reviewed articles concluded that it is critical for consumers and food handlers to be well informed about proper food handling practices in order to prevent crosscontamination and food poisoning.

On the other hand, there was a study conducted by Aimi et al. (2018) among food handlers in a public university in Malaysia had revealed that the respondents that had a good level of knowledge obtained low scores of attitude and practices regarding food safety and food poisoning prevention. The results may indicate that a high degree of awareness is sufficient to ensure that people comply with the guidelines on food safety and the prevention of food poisoning due to some of the obstacles as addresses in the Health Belief Model (HBM). According to the Health Belief Model (HBM), individuals will adopt preventive health behaviours when they know and believe that they are at risk of disease (perceived susceptibility) which may result in a disease that is harmful to their health (perceived severity). There is a shift in conduct that can help avoid or minimize the risk and seriousness of the disease (perceived benefits). There are, however, social, mental or physical barriers to the success of these behaviours (perceived barriers). Perceived vulnerability and severity can energize individuals to take action to change their behaviour to perform preventive behaviour (Bolte, 2013). There are still many people who have not understand the value of food safety knowledge, attitude and practices in the prevention of cross-contamination and food poisoning (Norazmir et al., 2012). This may, therefore, mean that Malaysia still needs to step up its efforts to prevent food poisoning among the population, in particular 
consumers, due to limited consumer-oriented study.

\section{Conclusion}

Clear evidence has shown that a high degree of knowledge does not guarantee a positive attitude and practice towards the prevention of food poisoning due to certain obstacles, including social, mental or physical obstacles to the success of such behaviour. It is therefore important to enhance knowledge, attitudes and practices of food poisoning and its prevention in the population. The studies reviewed have shown that sociodemographic characteristics affect the degree of knowledge, attitude and practice of food safety and the preventive of food poisoning. These findings can guide health education programs to pay more attention to increasing the level of KAP among communities in order to reduce cases of food poisoning specifically in Malaysia. Preventive measures to increase the level of KAP must be considered in order to minimize cases of foodborne diseases. Approach to educating people in the field of foodborne prevention can be rendered in the future by considering the target population and their socio-demographic profile. This reviewed literature will contribute to the literature of the future KAP study on food poisoning prevention and will serve as an eyeopener for future studies to increase knowledge, attitude and practice among consumer.

\section{Conflict of interest}

No conflict of interest among all the authors.

\section{Acknowledgement}

This study was supported by the Malaysia Research University Network (MRUN) UPM grant: UPM/8004/11/MRUN/2018/5539240.

\section{References}

Abdullah, M.F.S. (2015). Food safety knowledge, attitude, and practices on food handlers in food courts, Putrajaya, Malaysia. Selangor, Malaysia: Universiti Putra Malaysia, MSc. Thesis.

Abdullahi, A., Hassan, A., Kadarman, N., Saleh, A., Baraya, Y.S. and Lua, P.L. (2016). Food safety knowledge, attitude, and practice toward compliance with abattoir laws among the abattoir workers in Malaysia. International Journal of General Medicine, 2016(9), 79-87. https://doi.org/10.2147/ IJGM.S98436

Abdul-Mutalib, N.-A., Abdul-Rashid, M.-F., Mustafa, S., Amin-Nordin, S., Hamat, R.A. and Osman, M. (2012). Knowledge, attitude and practices regarding food hygiene and sanitation of food handlers in Kuala Pilah, Malaysia. Food Control, 27(2), 289293. https://doi.org/10.1016/j.foodcont.2012.04.001

Aimi, M.M., Nor, A.A. and Rahman, M.H. (2018). Knowledge, Attitude, and Practice toward Food Poisoning among Food Handlers and Dietetic Students in a Public University in Malaysia. Journal of Pharmacy and Bioallied Sciences, 10(4), 232239. https://doi.org/10.4103/JPBS.JPBS_141_18

Ajibola, L.S.A., Shohaimi, S., Adam, M.B., Nadzir, M.N.H.M. and Segun, O.E. (2018). Systematic review of knowledge, attitude, and practices regarding dengue in Malaysia. Journal of Applied Pharmaceutical Science, 8(12), 80-91. https:// doi.org/10.7324/JAPS.2018.81221

Ali, A.N., Jie, J.S., Prajapati, S.K., Ahmed, N.Z., Iqbal, M.Z. and Alshammari, T.M. (2018). A KAP study on food safety and hygiene among private university students in Kedah state, Malaysia. Journal of Natural Remedies, 18(3), 113-121. https:// doi.org/10.18311/jnr/2018/22289

Ali, A.N., William, A.F., Prajapati, S.K. and Ahmed, N.Z. (2018). A KAP Study on Food Safety and Hygiene Among Private University Students in Kedah State, Malaysia. Journal of Natural Remedies, 18(3), 113-121. https://doi.org/10.18311/ jnr/2018/22289

Asmawi, U.M.M., Norehan, A.A., Salikin, K., Rosdi, N.A.S., Munir, N.A.T.A., Basri, N.B.M., Selamat, M.I. and Md Nor, N. (2018). An Assessment of Knowledge, Attitudes and Practices in Food Safety Among Food Handlers Engaged in Food Courts. Current Research in Nutrition and Food Science, 6 (2), 9. https://doi.org/10.12944/CRNFSJ.6.2.09

Auad, L.I., Ginani, V.C., Stedefeldt, E., Nakano, E.Y., Nunes, A.C.S. and Zandonadi, R.P. (2019). Food safety knowledge, attitudes, and practices of brazilian food truck food handlers. Journal of Nutrients, 11(8), 1-19. https://doi.org/10.3390/ nu1 1081784

Bolte, B.J. (2013). Using The Health Belief Model To Determine Differences In University Foodservice Employees' Beliefs And Perceptions About Handwashing And Foodborne Illness. Kansas, USA: Kansas State University, MSc. Thesis.

CDC. (2019). Foodborne Illnesses and Germs | Food Safety | CDC. Retrieved July 15, 2019, from CDC website: https://www.cdc.gov/foodsafety/foodbornegerms.html

Commissioner of Law Revision Malaysia. (2006). Laws of Malaysia (Act 507): Abattoirs (Privatization) Act 1996. Malaysia. 
Dora-Liyana, A.L., Mahyudin, N.A., Ismail-Fitry, M.R., Ahmad-Zaki, A. and Rasiyuddin, H. (2018). Food Safety and Hygiene Knowledge, Attitude and Practices among Food Handlers at Boarding Schools in the Northern Region of Malaysia. International Journal of Academic Research in Business and Social Sciences, 8(17), 238-266. https:// doi.org/10.6007/IJARBSS/v8-i17/5228

Food Safety and Quality Division Ministry of Health Malaysia. (2016). Annual Report Food Safety and Quality Division 2016. Malaysia: Food Safety and Quality Division Ministry of Health Malaysia. Retrieved from http://fsq.moh.gov.my/v6/xs/dl.php? filename $=$ cf0bba514f8c1af4d185a64ca31f4562.pdf

Halim, M.H.A.A. Nagaretnam, L., Azman, S.A.N., Saliluddin, S.M. and Mahmud, A. (2014). Association between knowledge, attitude and practice (KAP) and hygiene status of food handlers and premises in cafeterias of a public university in Malaysia. International Journal of Public Health and Clinical Sciences, 1, 180-188.

Ismail, F.H., Chik, C.T., Muhammad, R. and Yusoff, N.M. (2016). Food Safety Knowledge and Personal Hygiene Practices amongst Mobile Food Handlers in Shah Alam, Selangor. Procedia - Social and Behavioral Sciences, 222, 290-298. https:// doi.org/10.1016/j.sbspro.2016.05.162

Lee, H.K., Abdul Halim, H., Thong, K.L. and Chai, L.C. (2017). Assessment of food safety knowledge, attitude, self-reported practices, and microbiological hand hygiene of food handlers. International Journal of Environmental Research and Public Health, 14 (55), 1-14. https://doi.org/10.3390/ijerph14010055

Mahmood, K., Khalid, J., Kamilah, H., Ali, A.J., Muhammad, L. and Ariffin, F. (2018). An Empirical Study of Food Safety, Food Handling, and Food Poisoning Awareness Among Foreign Students in Penang, Malaysia. International Journal on Advanced Science Engineering Information Technology, 8(1), 150-156. https://doi.org/10.18517/ ijaseit.8.1.3731

Ministry of Health Malaysia. (2018). Number of cases and incidence rate of communicable diseases by state, Malaysia. Retrieved from Ministry of Health Malaysia website: https://www.moh.gov.my/moh/ penerbitan/MYHAAG2018.pdf

Mohd Firdaus Siau, A., Son, R., Mohhiddin, O., Toh, P.S. and Chai, L.C. (2015). Food court hygiene assessment and food safety knowledge, attitudes and practices of food handlers in Putrajaya. International Food Research Journal, 22(5), 1843-1854.

Moreb, N.A., Priyadarshini, A. and Jaiswal, A.K. (2017). Knowledge of food safety and food handling practices amongst food handlers in the Republic of Ireland. Food Control, 80, 341-349. https:// doi.org/10.1016/j.foodcont.2017.05.020

Mustaffa, N.A., Rahman, R.A., Hassim, M.H. and Ngadi, N. (2017). Evaluation of Knowledge, Attitude and Practices of Food Handlers in Campus Cafeterias. Chemical Engineering Transactions, 56, 1297-1302. https://doi.org/10.3303/CET1756217

Nee, S.O. and Sani, N.A. (2011). Assessment of Knowledge, Attitudes and Practices (KAP) Among food handlers at residential colleges and canteen regarding food safety. Sains Malaysiana, 40(4), 403410.

Norazmir, M.N., Noor Hasyimah, M.A., Siti Shafurah, A., Siti Sabariah, B., Ajau, D. and Norazlanshah, H. (2012). Knowledge and practices on food safety among secondary school students in Johor Bahru, Johor, Malaysia. Pakistan Journal of Nutrition, 11 (2), 110-115. https://doi.org/10.3923/ pjn.2012.110.115

Norhaslinda, R., Norhayati, A.H. and Mohd Adzim Khalili, R. (2016). Knowledge, attitudes and practices (KAP) on good manufacturing practices (GMP) among food handlers in Terengganu hospitals. International Journal of Pharmacy and Pharmaceutical Sciences, 8(11), 53-59. https:// doi.org/10.22159/ijpps.2016v8i11.13000

Rahman, M.M., Arif, M.T., Bakar, K. and Tambi, Z. (2012). Food Safety Knowledge, Attitude and Hygiene Practices Among Street Food Vendors in Northen Kuching City. Journal of Borneo Science, 31, 107-116.

Rosnani, A H., Son, R., Mohhidin, O., Toh, P.S. and Chai, L.C. (2014). Assessment of knowledge, attitude and practices concerning food safety among restaurant workers in Putrajaya, Malaysia. Food Science and Quality Management, 32, 20-28.

Ruby, G.E., Ungku Fatimah, U.Z.A., Lihan, S., Noorahya, N.J. and Son, R. (2019a). A cross sectional study on food safety knowledge among adult consumers. Food Control, 99, 98-105. https:// doi.org/10.1016/j.foodcont.2018.12.045

Ruby, G.E., Ungku Fatimah, U.Z.A., Lihan, S., Noorahya, N.J. and Son, R. (2019b). Self-reported Food Safety Practices Among Adult Consumers in Sibu, Malaysia: A Cross-sectional Study. Food Protection Trends, 39, 366-376.

Saipullizan, S.N.A., Mutalib, S.A. and Sedek, R. (2018). Knowledge, Attitude and Practice of Food Utensils Hygiene amongst Food Handlers in Kuala Pilah, Negeri Sembilan, Malaysia. Journal of Sains Malaysiana, 47(7), 1527-1533. https:// 
doi.org/10.17576/jsm-2018-4707-21

Shaffril, H.A.M., Samah, A.A., Samsuddin, S.F. and Ali, Z. (2019). Mirror-mirror on the wall, what climate change adaptation strategies are practiced by the Asian's fishermen of all? Journal of Cleaner Production, 232, 104-117. https://doi.org/10.1016/ j.jclepro.2019.05.262

Syahira, S., Huda, B.Z. and Mohd Rafee, B.B. (2019). Factors Associated with Level of Food Safety Knowledge among Form Four Students in Hulu Langat District, Selangor. International Journal of Public Health and Clinical Sciences, 6, 252. https:// doi.org/10.32827/ijphcs.6.2.252

WHO (World Health Organization). (2001). Foodborne Disease: A Focus for Health Education - WHO OMS. Retrieved February 1, 2020, from http:// apps.who.int/bookorders/anglais/detart1.jsp? codlan $=1 \& \operatorname{codcol}=15 \& \operatorname{codcch}=475$

WHO (World Health Organization). (2018). E. coli. Retrieved February 6, 2020, from WHO website: https://www.who.int/news-room/fact-sheets/detail/ecoli

WHO (World Health Organization). (2019). Food safety. Retrieved January 31, 2020, from WHO website: https://www.who.int/en/news-room/fact-sheets/ detail/food-safety

Woh, P.Y., Thong, K.L., Behnke, J.M., Lewis, J.W. and Mohd Zain, S.N. (2016). Evaluation of basic knowledge on food safety and food handling practices amongst migrant food handlers in Peninsular Malaysia. Food Control, 70, 64-73. https://doi.org/10.1016/j.foodcont.2016.05.033 